International Journal of Instruction e-ISSN: 1308-1470 • www.e-iji.net
July $2019 \bullet$ Vol.12, No.3

p-ISSN: 1694-609X

pp. 167-182

Received: 06/11/2018

Revision: 23/03/2019

Accepted: 29/03/2019

OnlineFirst:22/04/2019

\title{
Student Verbal Interaction in Geometry Problem-Solving Through Cognitive Activities
}

\author{
Syarifudin \\ Graduate Program, Universitas Negeri Malang, Indonesia,
}

syarifudin.1603119@students.um.ac.id

Purwanto

Universitas Negeri Malang, Indonesia, purwanto.fmipa@um.ac.id

Edy Bambang Irawan

Universitas Negeri Malang, Indonesia, edy.bambang.fmipa@um.ac.id

I Made Sulandra

Universitas Negeri Malang, Indonesia, made.sulandra.fmipa@um.ac.id

Ummu Fikriyah

SMPN 4 Guling, Pasuruan, Indonesia, ummufikriyah39180@gmail.com

This qualitative study aimed at describing student verbal interaction verbally through cognitive activities consisting of procedural, disputational, and exploration in solving geometry problems. This research was in the form of students' verbal interaction activities in group discussion which decribe students' thinking process in detail, both the correct and incorrect thinking process, when conveying their ideas to their friends to solve a problem. The data were collected through a video recording and made in the form of dialogue transcriptions. The research results showed that the form of student verbal interaction on the procedural activity namely (1) students conveyed their ideas to their peers without arguing with each other; (2) discussion activities with planning as its nature; (3) students shared information used in problem-solving. The form of student verbal interaction on the disputational activities were (1) students responded to each other ideas, suggestions, or answers between individuals; (2) students defended each other's ideas or answers so that it triggered a group discussion; (3) the activities would end when all the group member have the appropriateness of the thinking process from the discussed problems.

Keywords: verbal interaction, geometry problem, procedural, disputational, exploration

Citation: Syarifudin, Purwanto, Irawan, E. B., Sulandra, I. M., \& Fikriyah, U. (2019). Student Verbal Interaction in Geometry Problem-Solving Through Cognitive Activities. International Journal of Instruction, 12(3), 167-182. https://doi.org/10.29333/iji.2019.12311a 


\section{INTRODUCTION}

Geometry is one of the learning materials in school mathematics. In the level of Junior High Schools, Geometry materials include the correlation between lines, angles, triangles and squares, Pythagoras theoreme, circles, cubes, prisms, pyramids, nets, congruence, tubes, cones, balls, and use them in problem-solving. Through learning Geometry materials, the students are expected to have geometry skills to solve the problems. According to National Council of Teachers of Mathematics (NTCM: 2000), it is stated that geometry skills that students should have are the ability of character analysis and the character of the shapes of geometry, both two-dimensional geometry and three-dimensional as well, and the ability to make mathematics argumentations about the correlation of geometry with others and use the visualisation, spatial reasoning, and geometry model to solve the problems. Therefore, if the students have geometry skills, it will be easier for them to solve mathematics problems, especially geometry problems. However, in facts, the students still find difficulties in learning and solving geometry problems. For example, based on international comparative tests, such as Trends in International Mathematics and Science Study (TIMSS) and Programme for International Student Assessment (PISA), it is stated that they expressed their dissatisfaction with students' understanding in geometry (Close, 2013; Halat \& Sahin, 2008; Steele, 2013). Based on those findings about the dissatisfaction with students' understanding in geometry, one of the contribution of this study is that this study can be used as a reference in creating lesson plans focusing on cognitive activity through verbal interaction implemented in group discussion.

Group discussion is an activity involving more than one individual to interact with the same group member in solving a problem. The ways of positioning their members in the group discussion immensely help to maximize their activity in knowledge construction. In line with the statement of Nilsson \& Ryve, (2010) that the group member involvement in the discussion can maximize the contribution of the individuals to solve a certain problem. Weber et al. (2008) said that if students often challenge the arguments conveyed by their peers when presenting mathematical material, then challenging activities can invite students directly to understand mathematical principles or indirectly as motivation to understand mathematics. Sfard \& Kieran (2001) state that to produce a fruitful discussion needs positive feedbacks from others harmoniously with what is expected by the speaker. The occurrence of mutual response to the material discussed from the problems to be discussed is because some members of the group have not understood it well. In order to homogenize the understanding, an interaction pattern design is needed for problem-solving.

Several studies on the student interaction pattern in problem-solving in the group are stated by (Barron, 2003; Lai \& White, 2014; Watson \& Chick, 2001). Barron (2003) mentions that interacting collaboratively results in better problem-solving and will give a positive impact on learning results. Watson \& Chick (2001) identify frameworks of cognitive, social, and other factors to influence the results of problem-solving achieved using the collaboration. Lai \& White (2014) said that problem-solving carried out in group discussion activities would have a positive impact if properly coordinated, and 
had a negative impact if it was not well coordinated. Problem-solving done in groups can help speed up finding the problem-solving process. Therefore, collaborative activities are often seen by students as activities that complement each other's ideas by offering parts of information that do not yet exist as long as they are needed in solving problems (Francisco \& Maher, 2005). Furthermore Mueller et al. (2016) stated that students collaborate by responding to statements from their colleagues to jointly build ideas, but in other cases, students can present their ideas formed from other people's ideas to be expanded or modified. The activities to transform, construct, and or modify ideas between one student and another would be studied deeper on the verbal interaction activities.

Verbal interaction is an activity connecting one person to another through the use of language. Furthermore, Tisher (1971) states that verbal interaction is a conversation between two or more. Verbal interaction activities will direct students to understand the results of their thoughts. Furthermore, verbal interactions cause greater understanding among students. Sangin et al. (2008) stated that verbal interaction can trigger the grounding needs which lead to the more complex conversation. The grounding is defined as a medium where the speaker will check the statement said to the interlocutor or improve the misunderstanding (Clark \& Brennan, 1991). Thus, student verbal interaction in this research is the conversation activity of one person to another by understanding each other on their thoughts in problem-solving.

The verbal interaction research has been long conducted by some experts, for example Webb, $(1985,1991)$ who studied on student verbal interaction on a small group in mathematics class. Webb examined and analyzed factors used to predict the peer interactions in the mathematics group and discuss the strategy to from group interaction. Different from what is investigated by Saleh et al. (2007) who tested on the regulation of structured collaboration to overcome the absence of group members. The research results showed that it positively affects the ability of group members and did not reduce the scores of high-ability students. Research on verbal interactions continues to be done in different ways. For example Blatt et al. (2008) analyze teacher-student verbal interactions in feedback activities at the level of verbal dominance, feedback balance, and cognitive level. The results of his research indicate that the teacher talks with his students as much as $(65.2 \%)$. Although, some corrective feedbacks are $(20.6 \%)$ and positive teachers' utterances are $(33.5 \%)$ or neutral are $(45.9 \%)$. Cognitively, teacher utterances occur on the factual level (lowest) $(74.3 \%)$. The interaction analysis enables us to describe 3 dimensions of teacher-student feedback is verbal dominant, positive corrective balance, and cognitive level. Interaction analysis enables us to describe the 3-dimensional feedback of teacher-student which is the verbal dominant, positive corrective balance, and cognitive level. Assessing these dimensions provides information about two feedback indices that are theoretically important to provide effectiveness to student involvement and balance of feedback.

The research implementation on teacher verbal interaction with students or student with other students besides performed in a conventional way, it can also be performed using visual media. For example, Sangin et al. (2008) conducted research using a multimedia 
on paired group interaction patterns. His research was about analyzing verbal interactions in collaborative learning to see an understanding of the effects of animation and the effects of the presence of snapshots. The results of his study did not show differences in terms of verbal categories between two versions of learning material, namely static images versus animated images. The pairs who are equipped with continuous snapshots of the multimedia sequence produce fewer speeches compared to participants without a snapshot. Research activities on verbal interactions were also carried out by (Lamb et al. 2000; Orbach \& Lamb, 2000) which focus the research on the new words uttered by a child in responding to a different interviewer.

Therefore, the interesting aspect that would be further studies is a study focusing on the student verbal interaction through three cognitive activities namely procedural, exploration, and disputational activities. These three activities are initiated by the opinion of (Mercer, 1994;1996) about three types of conversation sequences that are used to represent the process of thinking through speaking which is talking disputation, talking cumulatively, talking exploration. Kumpulainen \& Mutanen (1999) introduces descriptive systems of analysis of peer group interactions. This method takes a dynamic approach and is oriented towards the interaction process which is seen as social and situational activities developed based on changes in time-by-time student interactions. This method consists of a three-dimensional analysis of peer group interactions by focusing on verbal function, cognitive processing, and social processing. In cognitive processing, there are three activities, namely procedural, exploration, and disputational activities. This was further developed by Sánchez et al. (2013) who introduced an analysis framework to analyze teacher-student verbal interaction in the learning situation.

Sánchez et al. (2013) presents the interaction analysis framework which considers two dimensions which are the dimension that correlates by seeing the interacting group and the second dimension considers a relational variable. The developed relational variables are specific language, cognitive processing, social management, and relational. Meanwhile, Kumpulainen \& Mutanen (1999) constructing a framework for analyzing interactions in small groups by focusing on verbal function, cognitive processing, and social processing. These two studies illustrate the analytical framework in interactions followed by an introduction to empirical examples. Began by Sánchez, Escudero, Kumpulainen \& Mutanen's opinion on the three-analysis framework in the verbal interaction, therefore this research focuses on describing the student-student verbal interaction in the procedural, disputational, and exploration activities.

Furthermore, Sánchez et al. (2013) explains that the three analysis frameworks in the verbal interaction are procedural category which describes the characterization of characteristics in peer group activities when carrying out routine tasks without thorough planning or thinking coherently with positive but not critical decision making. Both categories of Exploration are seen as the most effective mode of relating to fostering critical thinking and cognitive development (Kumpulainen \& Mutanen, 1999; Mercer, 1996) this was signified by "critical and exploration activities which include planning, hypothesis testing, evaluation, and experimenting" (Kumpulainen \& Mutanen, 1999: 
457). The third category or Disputational (dispute) is signified by the disagreement of group members in decision making (Mercer, 1996).

Based on the explanation from several results in this manuscript, then a further and deeper study needs to be taken, a study that will describe the process of verbal interaction of students and the relationship of verbal interaction activities among students with one another from procedural, exploratory, and disputational activities. This study took a case study in a group of students consisting of five students. The determination of one group is used in this study because it can give rise to verbal interaction activities in procedural, disputational, and exploration activities. Therefore, in this article, the researcher explained the data in every 3 cognitive activities. This was due to the researcher wanted to get more comprehensive data from the 3 activities and therefore, it can be used as a reference in creating a lesson plan. The purpose of the study was to describe the verbal interactions of students verbally through cognitive activity consisting of procedural, disputational, and exploration activities in solving geometric problems. The advantage of this research is to be able to find out the students' thinking processes through verbal communication during problem-solving. Another aspect is also able to differentiate the students' thinking process through verbal interaction in the procedural, disputational, and exploration activities. Consequently, this study could describe that through verbal interaction, the students' thinking process, both the right-thinking process and the wrong as well, in detail when they tried to solve the problems, could be identified. The significance of this study is that it can facilitate the teachers to evaluate and assess the learning process of their students and it can be used as a reference to develop the theory of students' thinking process through verbal interaction in solving geometry problems, and also as a reference in creating a lesson plan of Mathematics learning focusing on the activity of students' interaction process.

\section{METHOD}

\section{Design}

This research design is a qualitative research with a case study approach. A case study was employed to investigate the student's verbal interaction in completing the geometry problems. Creswell, (2012) mentioned that case studies are research strategies in which researchers carefully investigate a program, event, activity, process, or group of individuals. The study investigated a case study in a group of students consisting of five people who were carrying out discussion activities to solve the problem.

\section{Instrument}

The instruments in this research were in the form of one essay question on a geometry problem. The students' task is to discuss with the group member on the problem-solving provided by the researcher. The problem in this study is "if there are 100 equilateral triangles and 60 squares with each having the same side length, how many models are formed images of cubes, beams, prisms, and pyramid" Note on the question is if triangles or squares have been used to draw the intended geometry figures, then it can no longer be used to create another geometry figure. 


\section{Research Subjects}

The research subjects were the eighth graders of Junior High School 2 Grati. Three students with high competence and two students with moderate competencies were selected based on the teacher's recommendations. The five subjects must also have the criteria to communicate verbally the results of their mathematical thinking properly. The choice of this subject is based on the teacher's recommendation because the teacher has observed students' oral communication skills during the mathematical problem-solving process that has been given. Then, the teacher classified the students' oral communication skill into two categories, i.e., medium and high, based on the mean score of the results of observation sheet fulfilled by the teacher for each student.

\section{Research Procedure and Data Collection}

This research was started with instrument preparation, i.e. making one question dealing with geometry. Then, the five predetermined subjects were grouped into one small group. Their task was to discuss the geometry problem that has been provided by the researcher. They solved the provided problem by communicating verbally their ideas or ideas to other friends. The activity continued until it finds a solution to the problem that is being faced. Along with the discussion activity verbally, the researcher recorded these five students. The researcher made an audio-visual recording to record students' verbal activities and their expressions during discussion activity to solve the problems. Along with recording activities, the researcher also recorded several student activities that were considered important as support data.

\section{Data Analysis}

The process of data analysis was carried out through 6 stages, i.e. (1) transcribing the verbal data collected; (2) reviewing all available data including the field notes from observations and the results of problem solving written by students; (3) grouping data in the form of conversational transcripts of students' verbal interactions into three cognitive activities of students, i.e. (a) procedural activities, (b) exploration activities, and (c) disputational activities; (4) analyzing students' verbal interactions based on procedural, exploratory and disputational activities; (5) analyzing the interesting things; (6) makig conclusions from the findings. In every cognitive activity, whether it is procedural, disputational, or exploration, in the presentation of data transcription of students' conversation, the researcher gave an elaboration based on the students' meaning and intention.

\section{FINDINGS}

The activity of geometry problem-solving by a group of students was conducted through a discussion. There were five people who performed the discussion symbolized with S1, S2, S3, S4, and S5. The students with a high competence were S1, S3, and S5, while the students with intermediate competence were S2 and S4. Each of the five students began problem-solving by understanding the questions that had been provided. The discussion activity began by S1 explaining the intent and purpose of the question. After several group members could understand from the problem, then a discussion activity took 
place to find a solution to the problem. The following is the description of the five students' verbal interactions in cognitive activities in the form of procedural, disputational and exploration activities when solving geometry problems.

\section{Procedural Activity}

The procedural activity is an activity describing the characteristics of the nature of peer group activities is understood as the implementation of routine tasks without thorough planning. This activity was performed by students in solving problems without thinking coherently and directly making decisions positively but not critically. In the procedural problem-solving activity by a group of students, it can be seen the following quotations.

1. S1 : Here they are... There are 100 triangles and 60 squares to construct cubes, beams, prisms, and pyramid (S1 explains to S2, S3, S4, and S5 about the meaning of the question)

2. S2 : This is how the illustration of the figures looks like.... (S2 explains more to $\mathrm{S} 1, \mathrm{~S} 3, \mathrm{~S} 4$, and S5 that the question instructs to create cubes, beams, prisms, and pyramid)

3. S3 : There are triangle and square (S3 conveys his/her ideas to all friends on what are needed to construct cubes, beams, prisms, and pyramid namely triangle and square)

4. S1 : Oh I see... what is more? (S1responds to S3 and invites his/her friends to solve the problems by prioritizing first on the cube)

5. S3 : That is correct (S3 supports S1's to construct a cube

6. S1 : Yes, let's use up the triangle and square to construct a cube (S1 invites all friends to construct the geometry figures by using up all triangles and squares)

7. S4 : That's correct (S4 responds to S1's opinion)

8. S5 : I agree (S5 responds to $\mathrm{S} 1$ 's opinion)

The verbal interactions in the discussion describe the problem-solving on constructing cube, beam, prism, and pyramid and focusing on constructing a cube. S1 students (line 1) began by explaining to all their friends that there were 100 triangles and 60 squares to make cubes, beams, prisms, and pyramid. The same goes for other students who conveyed ideas so that communication was established between them. In this activity, describing procedural activities with features such as in line 5, the S3 delivered a statement supporting the S1 without a thorough plan for the need for triangles and squares that must be used to construct the intended space. Based on the results of overall observations on procedural activities, it can be concluded that these activities can lead to student activities about conveying ideas, suggestions, or answers to all of their friends without any activity to argue with each other. The activities tend to discuss the aspects with planning as its nature. This activity tends to remind each other about the material that will be used for problem-solving. 


\section{Disputational Activities}

These activities are signified with the disagreement by the other group members who make a decision. The following is the quotations in the transcript of the student verbal interaction to solve the geometry problems.

9. S5 : how to make a pyramid constructed from squares (S5 asks all friend on the figure shape constructed from several squares)

10.S1 : such as this (S1 responds to S5 by showing the figure in his/her answer)

11. S2 : this way, right? (S2 asks the answer already shown by S1 while looking at the answer)

12. S3 : really? (S3 sees the pyramid figure shown by $\mathrm{S} 1)$

13. S4 : oh ... (S4 also sees the answer from S1)

14.S5 : why is it like that? Why not like this? (S5 shows the prism figure he/she made to $\mathrm{S} 1$ )

15. S1 : that's prism (S1 blames on the prism figure by S5)

16. S2 : it can also be like this (S2 shows rectangular pyramid he/she made to S1

17. S1 : it's the same thing, what's important is a prism is drawn and constructed from triangle and rectangle ( $\mathrm{S} 1$ emphasizes on the answer stated by $\mathrm{S} 2$ )

18. S4 : like this (S4 shows his/her figure to $\mathrm{S} 1)$

19. S2 : like this (S2 emphasizes the figure on S5).

20.S1 : Yes, this way (S1 shows his/her figure to all his/her friends)

21.S5 : oh I see ... (S5 realizes from the statement of his/her friends that what he/she drew is prism)

22. S4 : Look, these are rectangular and triangle, what you made is a prism, that rectangular prism is made of six triangles, where two triangles are joined into one square. (S4 explains to S5)

23. S1 : that's correct... (S1 supports the opinion of S4)

24. S5 : I understand... (S5 states an understanding from S4's explanation)

25.S1 : actually, not only constructed from all triangles, it can be from square for the base part (S1 also emphasize S4's explanation to all group members using a different way)

The dialog describes the students' activity in solving a pyramid drawing problem, this verbal interaction began by S5 (line 6) who asks to his/her friends on how to draw a pyramid constructed from squares. In the dialog, S1 (line 10) responds immediately by showing the answer to the S5 and so does the other students. However, S5 (line 14) is still confused and has not agreed with the opinions of his friends so he/she needs an explanation from the other group members. S2 (line 16) continues the description to S5 and is confirmed again by S1 (lines 17 and 25) and S4 (line 22). Based on the results of overall observations on disputational activities, it can be concluded that activities can improve students to convey ideas, suggestions, or answers individually to other individuals. This activity tends to respond to each other's ideas, suggestions, or answers between individuals and if it is difficult for individuals to find a solution, there will be a discussion in groups. This activity will end when all group members have understood all the provided solution. 


\section{Exploration Activities}

This activity is marked with the critical and exploration activities by the group member including planning, hypothesis testing, evaluation, and experiment. The following is the student verbal interaction activity in the exploration category in solving geometry problems.

26. S2 : How about 20 squares to construct the cube? (S2 asks to all his/her friends)

27. S1 : This way ... there are four (base and top), there are four (front and back), and two (left and right). (S1 calculates the sides of the cubes while showing to all his/her friends, if the squares are used to construct the sides of the cube)

28. S4 : That's correct (S4 emphasizes on S1's opinion while calculating the sides of the beam)

29. S5 : All right (S5 emphasize on S1's statement while drawing)

$30 . \mathrm{S} 3$ : one, two, ..., ten (S3 responds to $\mathrm{S} 1$ 'opinion while calculating the sides of the squares used to construct the beam figure)

31. S1 : This is it... (S1 shows to all friends while calculating the number of squares needed to construct a beam)

32. S2 : oh I see (S2 responds to S1 while continue drawing)

33. S5 : this is how the figure looks like (S5 while showing the finished drawing to S1)

34. S1 : Yes, like that, but give dotted lines (S1 responds to S5'opinion while suggesting to draw dotted lines)

35. S2 : All right ... (S2 responds S1'opinion while drawing and sometimes while looking at the answers from S1, however the naming of the cubes is different from $\mathrm{S} 1$ )

36. S3 : Here it is, (S3 asks with $\mathrm{S} 2$ while numbering $1,2, \ldots, 10$ on the beam showing the number of squares)

37. S4 : All right ... (S4 responds the $\mathrm{s} 3$ statement while drawing beam by numbering $1,2, \ldots, 10$ on the beam showing the number of squares)

38. S5 : like this, All right? (S5 responds to S1 while writing the letters of ABIJ, IJDM, ... on the beam figures)

39. S1 : do you think this is beam figure? (S1 asked to S5 while showing the figure)

40. S5 : it is likely to be wrong (S5 respond to S1 and feels doubt on the beam he/she made)

41. S4 : no, there are beam and cube (S4 corrected S5's figure and explains the difference on beam and cube to S5)

The activities on the dialogue have explained the student verbal interactions on drawing a beam. The activity was initiated by S2's statement (line 26) about how to make beams arranged from 20 square. The activity was responded directly by S1, S4, S5, and S3 (lines 27-41) to compile plans, test hypotheses, conduct evaluations, and experiment with activities to arrange blocks of 20 square. This is like S1 evaluating the number of squares needed in drawing blocks (line 31). Based on the results of overall observations on exploration activities, it can be concluded that activities can lead to student creativity 
that invites or asks other friends, then other students participate in answering, agreeing so that planning activities, hypothesis testing, evaluation, and experimentation emerge. The activity tends to show each student solves the problem individually then conveys or tells on other students.

The following is the description specifically on student verbal interaction occurring during cognitive activities in geometry problem-solving.

Table 1

Descriptions of Student Verbal Interaction Activities on Cognitive Activities

\begin{tabular}{lll}
\hline \multicolumn{1}{c}{ Cognitive Activities } & \multicolumn{1}{c}{ Descriptions of Verbal Interaction } \\
\hline Procedural activities & - & $\begin{array}{l}\text { Student conveys ideas to his/her friends without any } \\
\text { argument to each other. } \\
\text { Discussion activity with the nature of planning according to } \\
\text { a certain problem. } \\
\end{array}$ \\
- & Student share information to be used in problem-solving. \\
\hline Disputational activities & - & $\begin{array}{l}\text { Students respond to each other's ideas, suggestions, and } \\
\text { answers. } \\
\text { - Activities lead to mutually defending ideas or answers that } \\
\text { lead to encouraging all students to communicate their ideas } \\
\text { through resolving disputes. }\end{array}$ \\
& - $\begin{array}{l}\text { Activities end when all the group members already have an } \\
\text { appropriate thinking process from the problem being faced. }\end{array}$ \\
\hline Exploration activities & - $\begin{array}{l}\text { Student asks an inviting question or asks to their friends. } \\
\text { Students respond to each other by doing planning } \\
\text { activities, testing hypotheses, evaluating, and } \\
\text { experimenting on the problems faced. } \\
\text { Problem-solving is performed individually with the results } \\
\text { conveyed to other friends. }\end{array}$ \\
\hline
\end{tabular}

\section{DISCUSSION}

An interesting aspect that is discussed in this research is the activities of student verbal interaction in problem-solving during the procedural, disputational and exploration activities. This verbal interaction activity begins with mutually reinforcing the understanding of one student with the other students regarding the problem of the problem that has been provided. Students give each other perceptions of the results of their understanding of the questions given where students from one another give a statement about the answers that will be written together. This is in line with the opinion of Gresalfi et al. (2009) states that negotiation process is needed to occur to strengthen the answer from each way of thinking. The activity of decision making is not enough by verbally; however, there were students who had not been sure on the answer from the agreement verbally and still looking at the friend's answer.

All students understand the given questions, here S1 who has a high competence initiated by giving a tutorial on how to solve the problem to all his/her friends. Students tend to discuss on aspects with the nature of planning, when conveying ideas or answers, they tend to remind each other and no arguments. I line with the opinion by Saleh et al. 
(2007) that when there is discussion in groups, the habits that arise in high-ability students tend to adopt the role of teachers who provide explanations and other types of assistance to low-ability students. This can be seen in the dialogue activities that occur in procedural activities, activities that lead to disputes, and exploration activities (lines 1, 10 and 27). Furthermore, the other students were still confused and asking questions to their friends so that collaborative activities took place to solve the problem (lines 12, 14, 21, and 38). This is in line with Bishop's opinion (2012) states that the way someone speaks and interacts is significantly affected by their ability. Individual's ability in identifying the given problems will be affected by experiences and knowledge of the individuals themselves (Allport, 1960). Experience and knowledge stored in memory will affect each individual to the stimulus that comes (Gagne, 1985). Experience will provide the shape and structure of the objects depicted by the senses, while knowledge will give meaning to objects, individuals, and people involved in the answers to available answers in the form of individual attitudes and behavior towards existing objects (Allport, 1960). Gagne (1985) also explains that someone's understanding depends on how much an individual have learned the stimulus or previous learning.

Students who have not possessed knowledge and experiences stored in the memory will find it difficult to explain the existing problems so that they need an explanation from friends (lines 9, 14, and 31). Here, there will be verbal interactions by students who have prior knowledge and experiences (line 4-6). Students who already mastered it would explain to their friends. Likewise, vice versa, for students who has not mastered would receive the knowledge and experience. From the results of the interaction between these students, it can be seen that the interactions that occurred were in accordance with Vygotsky's view of scaffolding, that one child can better guide other children in passing the ZPD (Zone of Proximal Development). Students who do not yet have the knowledge of the problem to be resolved will make some misidentification of the assumptions given at the time of expressing their opinions, resulting in wrong perceptions and errors in the answers. The wrong identification process is due to an understanding of wrong and limited concepts stored in memory. As a result, students with understanding and experience lack of wrong perception of the stimulus and the difficulty in choosing a strategy or determining the initial step of the answer. This is according to the research results by (Barnard, 2000; Weber, 2001). Chen, (2008) stated that the initial cause of students' failure in answering a question is due to the lacking of conceptual and strategic knowledge.

When all students have known and understood all answers from the sharing idea results or their verbal interaction activities through communication, next is each student individually would write the answers on the provided answer sheets (line 35-38). The existing answers will be represented in a real form. It was also found that some students have not yet confidently written their answers from their own thoughts. This means that in working memory students answers that have been mutually agreed upon are incomplete. This possibility occurs because the recipient of the information has not fully understood or has not yet received complete information. Some students still look back from their friends' answers which have been stated in real form. This is in accordance with the opinion of Kieran, (2001) who states that the incomplete information delivery 
will be responded back by the information recipient both verbally or written by the informant. After rechecking the answers from friends, then the student wrote their own answer. So that the answer from all group members can develop from what is already had with the knowledge gained from other students' explanations.

The last activity on the exploration activity is the students wrote the answers from the results of agreement of the group members by presenting it together. In reality, each student has their own way in presenting their answers (line 36 and 38). The five students wrote it in their own way. Their knowledge and understanding of these answers have been recorded in their respective long-term memory. The way students answered the given questions depends on the pattern of their interaction activities. The pattern of interaction activities has a correlation with the results of problem-solving. This is in line with the research results obtained by (Barron, 2000; Lai \& White, 2014; Watson \& Chick, 2001).

Therefore, this study can be used as a reference in creating a lesson plan, especially the lesson plan which focuses on collaborative activity of small group discussion with cognitive activities, whether it is procedural, disputational, or exploration. This is in line with the expectation of 2013-curriculum (K-13 curriculum) implemented in Indonesia and the $21^{\text {st }}$-century skills, such as critical thinking, creative and innovative, collaborative, and communication. A lesson plan is created based on some problems and their uniqueness, the guide to choose peer tutoring, and the instruments of learning evaluation process. The various problems with their uniqueness are made to arise the three cognitive activities. The choice of peer tutoring in each group should be done based on those who have good oral communication skills with medium or high category. The instruments of evaluation can be used to evaluate and assess the students' thinking process in discussion activity. Each indicator of the instruments of evaluation should be able to assess students' thinking process during verbal interaction in order to get the comprehensive data of the students' thinking processes.

\section{CONCLUSION}

Problem-solving activity was conducted by each student who has understood the given questions by reading it first. The verbal interaction activities were initiated by a student giving a question to the group members and others would respond using their own ways. The five students discussed together and helped each other to find the solutions to the provided problems by conveying ideas from their understanding, connecting ideas from their interlocutors to the level of knowledge they possessed, and giving as well as accepting ideas offered by their friends. Verbal interaction activities like this continue to occur until the end of the discussion which is summarized in three activities namely procedural, disputational, and exploration activities. More activities give rise to verbal interactions between students with one another occurring during disputational activities, followed by exploration, and procedural. In general, the form of verbal interaction of students in procedural activities is that students convey ideas to their friends without arguing with each other; activities discuss matters of a planning nature; and students provide information to each other to use in solving problems. The form of verbal interaction of students at disputational is that students respond to each other's ideas, 
suggestions or answers between individuals; students defend each other's ideas or answers giving rise to group discussion; and the activity will end if all group members already have a matching process of thinking of the issues discussed. Forms of students' verbal interactions in exploration activities, namely students give statements that are inviting or asking questions to other friends; other students respond by doing planning activities, testing hypotheses, evaluating, or experimenting with the statements submitted; and the problem-solving was conducted individually with the results conveyed to the group members. Further research can be conducted on the subject who have communication skills both verbal and written, or the verbally but unable to communicate in written. This is because this research only focused on the subjects' communication skills verbally.

\section{REFERENCES}

Allport, G. W. (1960). Attitudes in the History of Social Psychology. In Attitudes, edited by Neil Warren and Marie Jahoda. Middlesex, UK: Penguin, Harmondsworth, pp. $15-21$.

Barnard, T. (2000). Why Are Proofs Difficult? The Mathematical Gazette, 84(501), 415-422. https://doi.org/10.2307/3620770

Barron, B. (2000). Achieving Coordination in Collaborative Problem- Solving Groups. The Journal of the Learning Sciences, 9(4), 403-436. https://doi.org/10.1207/S15327809JLS0904

Barron, B. (2009). When Smart Groups Fail When Smart Groups Fail, 8406(2003), 307-359. https://doi.org/10.1207/S15327809JLS1203

Bishop, J. P. (2012). "She's always been the smart one. I've always been the dumb one": Identities in the mathematics classroom. Journal for Research in Mathematics Education, 43(1), 34-74. https://doi.org/10.5951/jresematheduc.43.1.0034

Blatt, B., Confessore, S., Kallenberg, G., \& Greenberg, L. (2008). Verbal interaction analysis: Viewing feedback through a different lens. Teaching and Learning in Medicine, 20(4), 329-333. https://doi.org/10.1080/10401330802384789

Chen, Y. (2008). from Formal Proofs to Informal Proofs-Teaching Mathematical Proofs with the Help Of Formal Proofs. International Journal of Case Method Research \& Application, $X X(4), 398-402$.

Clark, H. H., \& Brennan, S. E. (1991). Grounding in communication. Perspectives on Socially Shared Cognition. https://doi.org/10.1037/10096-006

Close, S. (2013). Mathematics items: Context and curriculum. In E. Eivers \& A. Clerkin (Eds.), National schools, international contexts: Beyond the PIRLS and TIMSS test results (pp. 153-176). Dublin, Ireland: Educational Research Centre.

Dynel, M. (2011). Revisiting Goffman's postulates on participant statuses in verbal 
interaction. Linguistics and Language Compass, 5(7), 454-465. https://doi.org/10.1111/j.1749-818X.2011.00286.x.

Francisco, J. M., \& Maher, C. A. (2005). Conditions for promoting reasoning in problem solving: Insights from a longitudinal study. Journal of Mathematical Behavior, 24(3-4), 361-372. https://doi.org/10.1016/j.jmathb.2005.09.001.

Gresalfi, M. S., Martin, T., Hand, V., \& Greeno, J. G. (2009). Constructing competence: An analysis of students' participation in the activity system of mathematics classrooms. Educational Studies in Mathematics, 70(1), 49-70. https://doi.org/10.1007/s10649-0089141-5

Halat, E., \& Sahin, O. (2008). Van Hiele levels of pre-and in-service Turkish elementary teachers and gender related differences in geometry. The Mathematics Educator, $11(1 / 2), 143-158$.

Kieran, C. (2001). The mathematical discourse of 13-year-old partnered problem solving and its relation to the mathematics that emerges. Educational Studies in Mathematics, 46(1995), 187-228. https://doi.org/10.1023/A:1014040725558

Kumpulainen, K., \& Mutanen, M. (1999). The situated dynamic of peer group interaction: An introduction to an analytic framework. Learning and Instruction, 9, 449-473.

Lai, K., \& White, T. (2014). How groups cooperate in a networked geometry learning environment. Instructional Science, 42(4), 615-637. https://doi.org/10.1007/s11251013-9303-4

Lamb, M. E., Sternberg, K. J., \& Esplin, P. W. (2000). Effects of Age and Delay on the Amount of Information Provided by Alleged Sex Abuse Victims in Investigative Interviews Author ( s ): Michael E . Lamb, Kathleen J . Sternberg and Phillip W . Esplin Published by : Wiley on behalf of the Society for Resear, 71(6), 1586-1596.

Mercer, N. (1994). The quality of talk in children's joint activity at the computer. Journal of computer assisted learning, 10(1), 24-32.

Mercer, N. (1996). The quality of talk in children's collaborative activity in the classroom. Learning and Instruction, 6(4), 359-377. https://doi.org/10.1016/S09594752(96)00021-7

Mueller, M., Yankelewitz, D., \& Maher, C. (2016). A framework for analyzing the collaborative construction of arguments and its interplay with agency Author ( $\mathrm{s}$ ): Mary Mueller, Dina Yankelewitz and Carolyn Maher Source: Educational Studies in Mathematics , Vol . 80 , No. 3 ( July 2012 ), pp . 369-387, 80(3), 369-387

National Council of Teachers of Mathematics (Ed.). (2000). Principles and standards for school mathematics (Vol. 1). National Council of Teachers of. 
Nilsson, P., \& Ryve, A. (2010). Focal event , contextualization , and effective communication in the mathematics classroom Author ( $\mathrm{s})$ : Per Nilsson and Andreas Ryve Source : Educational Studies in Mathematics, Vol . 74 , No . 3 ( July 2010 ), pp . 241-258 Published by: Springer Stabl. Educational Studies in Mathematics, 74(3), 241-258. https://doi.org/10.1007/s10649-010-9236-7.

Orbach, Y., \& Lamb, M. E. (2000). Enhancing children's narratives in investigative interviews. Child Abuse and Neglect, 24(12), 1631-1648. https://doi.org/10.1016/S0145-2134(00)00207-6

Saleh, M., Lazonder, A. W., \& Jong, T. (2007). Structuring collaboration in mixedability groups to promote verbal interaction, learning, and motivation of average-ability students. Contemporary Educational Psychology, 32(3), 314-331. https://doi.org/10.1016/j.cedpsych.2006.05.001.

Sánchez, V., García, M., \& Escudero, I. (2013). An analytical framework for analyzing student teachers' verbal interaction in learning situations. Instructional Science, 41(2), 247-269. https://doi.org/10.1007/s11251-012-9226-5

Sangin, M., Dillenbourg, P., Rebetez, C., Bétrancourt, M., \& Molinari, G. (2008). The effects of animations on verbal interaction in computer supported collaborative learning. Journal of Computer Assisted Learning, 24(5), 394-406. https://doi.org/10.1111/j.13652729.2008.00275.x.

Sfard, A., \& Kieran, C. (2001). Cognition as communication: Rethinking learning-bytalking through multi-faceted analysis of students' mathematical interactions. Mind, Culture, and Activity, 8(1), 42-76.

Steele, M. D. (2013). Exploring the mathematical knowledge for teaching geometry and measurement through the design and use of rich assessment tasks. Journal of Mathematics Teacher Education, 16(4), 245-268.

Vološinov, V. N. (1973). Verbal Interaction. Marxism and the Philosophy of Language, 8(1), 83-98.

Watson, J. M., \& Chick, H. L. (2001). Factors influencing the outcomes of collaborative mathematical problem solving: An introduction. Mathematical Thinking and Learning, 3(2-3), 125-173. https://doi.org/10.1080/10986065.2001.9679971

Webb, N. M. (1991). Example Partialcorrelation: Task-Related Verbal Interaction and Mathematics Learning in Small Groups: Journal for Research in Mathematics Education, 22(5), 366. https://doi.org/10.2307/749186

Webb, N. M. (1985). Verbal interaction and learning in peer-directed groups. Theory into practice, 24(1), 32-39.

Weber, K. (2001). Student difficulty in constructing proofs: The need for strategic knowledge. Educational Studies in Mathematics, 48(1), 101-119. 
https://doi.org/10.1023/A:1015535614355

Weber, K., Maher, C., Powell, A., \& Lee, H. S. (2008). Learning opportunities from group discussions: Warrants become the objects of debate. Educational Studies in Mathematics, 68(3), 247-261. https://doi.org/10.1007/s10649-008-9114-8 